\title{
AVALIAÇÃO DA ESPECIFICIDADE DE RIZOBACTÉRIAS ISOLADAS DE DIFERENTES ESPÉCIES DE Pinus sp. ${ }^{1}$
}

\author{
Juliana Margarido Fonseca Couto Brunetta ${ }^{2}$, Acelino Couto Alfenas ${ }^{3}$, Reginaldo Gonçalves Mafia ${ }^{3}$, José
} Mauro Gomes ${ }^{4}$, Daniel Breda Binoti ${ }^{5}$ e Ésio de Pádua Fonseca ${ }^{6}$

\begin{abstract}
RESUMO - Testou-se a especificidade das rizobactérias promotoras de crescimento em mudas de $P$. taeda L., P. oocarpa, P. elliottii Engelm. e P. caribaea var. hondurensis. Os isolados de rizobactérias UFV-AL9, UFV-AM5, UFV-AM2, UFV-F3, UFV-G2, UFV-G4, UFV-Z1, UFV-F6 e UFV-X2 foram inoculados por meio da aplicação de inóculo de rizobactérias em substrato de produção de mudas. Aos 150 dias de semeadura, avaliouse o peso de matéria seca de raízes e da parte aérea das mudas, bem como o índice de qualidade de Dickson. Foram constatadas interações significativas dos isolados e das diferentes espécies de pinus. Os incrementos da biomassa da parte aérea e do sistema radicular variaram conforme o isolado e a espécie de pinus, porém, de modo geral, foram observados maiores médias das mudas de P. taeda. As mudas de $P$. taeda, inoculadas com os isolados UFV-Z1 e UFV-AM5, apresentaram ganhos significativos de biomassa da parte aérea, do sistema radicular e do índice de qualidade de Dickson, em relação à testemunha. Nas mudas de $P$. elliottii, observouse também aumento significativo da biomassa da parte aérea, quando inoculadas com o isolado UFV-AM5 e do sistema radicular com os isolados UFV-X2, UFV-G2 e UFV-AM5. O isolado UFV-AM5 não se mostrou específico para essas variáveis, nas duas das quatro espécies estudadas (P. taeda e P. elliottii).
\end{abstract}

Palavras-chave: Pinus taeda, Pinus elliottii e Pinus caribaea var. hondurensis.

\section{EVALUATION OF SPECIFICITY OF RHIZOBACTERIA ISOLATED FROM DIFFERENT SPECIES OF PinUS sp.}

\begin{abstract}
The main objective of this paper was to test the specificity of plant growth-promoting rhizobacteria isolated from $\boldsymbol{P}$. taeda on other pinus species (P. elliottii, $\boldsymbol{P}$. oocarpa and $\boldsymbol{P}$. caribaea hondurensis). The rhizobacteria isolates UFV-AL9, UFV-AM5, UFV-AM2, UFV-F3, UFV-G2, UFV-G4, UFV-Z1, UFV-F6 and UFV-X2 were directly applied on the seedling sowing substrate. At 150 days of sowing, seedling root and aerial part dry matter weight, as well as Dickson's quality index were evaluated. Significant interactions among strains and different pine species were observed. Aerial part and root dry matter varied according to the strain and pine species, but generally the highest averages were presented on P. taeda seedlings. When inoculated with UFV-Z1 and UFV-AM5 strains, the $\boldsymbol{P}$. taeda presented significant differences for all variables. For $\boldsymbol{P}$. elliottii, seedlings inoculated with strains UFV-X2,UFV-G2 and UFV-AM5 and with UFV-AM5 also showed a significant increase in the aerial part and root biomass, respectively. Strain UFV-AM5 did not show specificity for these variables in two of the four analyzed species (P. taeda and P. elliottii).
\end{abstract}

Keywords: Pinus taeda, Pinus elliottii and Pinus caribaea var. hondurensis.

\footnotetext{
${ }^{1}$ Recebido em 15.01.2007 e aceito para publicação em 16.04.2007.

${ }^{2}$ Doutoranda em Ciência Florestal pela Universidade Federal de Viçosa (UFV), Viçosa-MG. E-mail: <juliana.brunetta@uol.com.br>.

${ }_{3}^{3}$ Departamento de Fitopatologia da UFV. E-mail: <aalfenas@ufv.br>; <rgoncalves@aracruz.com.br>.

${ }^{4}$ Professor Aposentado do Departamento de Engenharia Florestal da UFV.

${ }^{5}$ Graduação em Engenharia Florestal da UFV. E-mail: <danielbinoti@ hotmail.com>.

${ }^{6}$ Departamento de Agronomia da Universidade Estadual de Londrina, Londrina-PR. E-mail: <esiof@ uel.br>.
} 


\section{INTRODUÇÃO}

O Brasil possui uma das maiores áreas plantadas com coníferas do mundo, o que, aliado à riqueza das suas características edafoclimáticas, proporcionalhe uma vantagem sobre outras nações produtoras (NEVES et al., 2001). A área plantada com Pinus spp. ocupa aproximadamente 2.220 .000 ha, o fim atender à demanda de matéria-prima para produção de celulose, fabricação de móveis, chapas de composição e gomaresina (FAO, 2006).

A produção de mudas de pinus, ao contrário do eucalipto, ainda não sofreu grandes avanços tecnológicos. Atualmente, além da baixa tecnologia, o tempo necessário para formação das mudas é relativamente grande. Portanto, inovações que permitam maior eficiência no processo de produção de mudas é de grande importância. Nesse contexto, tem sido estudado que a inoculação de rizobactérias promotoras do crescimento de plantas pode promover aumento do crescimento e melhoria na qualidade de mudas de pinus(CHANWAY, 1997; BENT, 2000; ENEBAKeCAREY, 2004; ENEBAK, 2005; MAFIA et al., 2005).

Antes de 1989, eram raros os estudos referentes à promoção de crescimento de mudas de gimnospermas com o uso de rizobactérias (PROBANZA et al., 2002). Dentre esses, Parker e Dangerfield (1975) e PkojskaBurdziej (1982) estudaram os efeitos da rizobacterização em sementes de Pinus sylvestris e Pseudotsuga menziesii, respectivamente. Desde então, aumentou-se o interesse nesse tipo de estudo para coníferas, englobando várias espécies de Pinus, Picea, Tsuga e Pseudotsuga (CHANWAY e HOLL, 1992; LEYVAL e BERTHELIN, 1993; CHANWAY, 1995; ENEBAK, 2005).

O efeito no crescimento pode-se dá pela interação entre isolados de rizobactérias e genótipos da planta de interesse. Essa especificidade pode estar relacionada com a coexistência natural da planta hospedeira/bactéria ou com o compartilhamento metabólico entre plantas hospedeiras e bactérias, que independe de sua coexistência prévia (HOLL e CHANWAY, 1992; CHANWAY et al., 1988). Rizobactérias isoladas de espécies de diferentes plantas podem exibir especificidade na promoção biológica do crescimento (ENEBAK et al., 1998).

No Brasil não há estudos sobre a influência de rizobactérias sobre a promoção do crescimento de mudas de coníferas. Assim, este trabalho objetivou avaliar a especificidade de rizobactérias isoladas de mudas de $P$. taeda quanto à promoção de crescimentto em espécies de pinus ( $P$. taeda, $P$. elliottii, $P$. oocarpa e $P$. caribaea var. hondurensis).

\section{MATERIAL E MÉTODOS}

O experimento foi conduzido no Viveiro de Pesquisa do Departamento de Engenharia Florestal da Universidade Federal de Viçosa (UFV), em Viçosa, MG.

\subsection{Espécies e procedências das sementes de pinus}

A seguir, as sementes utilizadas e as empresas das quais respectivamente foram adquiridas empresas: P. taeda L. e P. elliotti Engelm., Klabin Florestal Paraná (Área de Produção de Sementes, Telêmaco Borba, Paraná); P. oocarpa, Duratex Florestal S.A. (Pomar de Sementes Clonal, Fazenda Monte Alegre, Agudos, São Paulo); e $P$. caribaea var. hondurensis, International Paper (Pomar de Sementes AMCEL/2, Morada Nova de Minas, Minas Gerais).

\subsection{Rizobactérias testadas}

Testaram-se os isolados UFV-AL9, UFV-AM5, UFVAM2, UFV-F3, UFV-G2, UFV-G4, UFV-Z1, UFV-F6eUFVX2, pré-selecionados de mudas de Pinus taeda e Pinus caribeae var. hondurensis, provenientes da Klabin Florestal Paraná e International Paper. As rizobacterias são mantidas em condições assépticas no Laboratório de Patologia Florestal.

As rizobactérias selecionadas foram testadas para P. elliottii, P. oocarpa, $P$. caribaea hondurensis e $P$. taeda, no estudo da interação entre isolados de rizobactérias e espécies de pinus.

\subsection{Produção de inóculo e inoculação dos isolados em substrato}

Para produção de inóculo, cada isolado de rizobactéria foi cultivado, separadamente, em placa de Petri, com o meio recomendado por Kado e Heskett (1970). Após a incubação por 24 h a $28^{\circ} \mathrm{C}$, no escuro, procedeu-se à raspagem do crescimento das rizobactérias, utilizando solução salina ( $\mathrm{NaCl}, 0,85 \%)$. A densidade ótica de cada suspensão foi ajustada para $0,2 \mathrm{de}$ absorbância em $540 \mathrm{~nm}$, o que corresponde, aproximadamente, a $10^{8}$ u.f.c. $\mathrm{mL}^{-1}$, conforme a correlação entre densidade ótica e número de unidades formadoras de colônias (u.f.c.), com base em Teixeira (2001). 
O inóculo foi aplicado ao substrato de produção de mudas (Plantmax ${ }^{\circledR}$ ), na proporção de $0,1 \mathrm{~mL}^{\mathrm{cm}-3} \mathrm{de}$ substrato antes da semeadura, em tubetes de $50 \mathrm{~cm}^{3}$. Um substrato umedecido com solução salina autoclavada na mesma proporção serviu como testemunha. Além da inoculação com os isolados de rizobactérias, realizou-se a aplicação de acículas picadas de Pinus, como fonte inicial de fungos micorrízicos, na proporção de 1:6 (p/p).

\subsection{Semeadura, adubação do substrato e condução do experimento}

Os tratamentos constaram da inoculação de mudas de P. taeda, P. oocarpa, P. elliotti e P. caribaea var. hondurensis cultivadas em tubetes com $50 \mathrm{~cm}^{3} \mathrm{de}$ substrato comercial Plantmax ${ }^{\circledR}$, com cada um dos isolados de rizobactéria separadamente. Foi mantido um controle sem inoculação.

As sementes de $P$. taeda foram previamente submetidas à quebra de dormência, por meio da estratificação em areia umedecida a $10^{\circ} \mathrm{C}$, por 26 dias.

A semeadura foi realizada diretamente nos tubetes, e aos 20 dias realizou-se o raleio, deixando-se apenas uma muda vigorosa no centro de cada tubete. Os tubetes foram inicialmente mantidos em casa de sombreamento ( $50 \%$ de luminosidade natural), acondicionados em bandejas planas com capacidade para 1.200 tubetes, suspensas a $80 \mathrm{~cm}$ do solo. Imediatamente após o raleio das plântulas, estas foram transferidas para casa de vegetação coberta com lona plástica transparente mais uma abertura lateral.

A ocupação das bandejas nos primeiros 30 dias foi de $100 \%$, deixando-se apenas uma linha vazia entre cada repetição. Após esse período, as mudas foram espaçadas para capacidade de $50 \%$ da bandeja.

A irrigação das mudas e os demais tratos culturais foram realizados conforme recomendações específicas para produção de mudas de pinus.

A adubação de base do substrato foi feita com 10 kg de NPK (20-0-20) e 4 kg de Fosmag 400 ${ }^{\circledR}$ (fosfato magnesiano) por $\mathrm{m}^{3}$ de substrato. Aadubação de formação iniciou-se aos 10 dias após a operação de raleio, em intervalos de 15 dias, com aplicação de $5 \mathrm{~mL}$ de solução, contendo $25 \mathrm{~kg}$ de superfosfato simples, $11 \mathrm{~kg}$ de sulfato de amônia e $5 \mathrm{~kg}$ de cloreto de potássio em $1.000 \mathrm{~L}$ de água.

\subsection{Delineamento experimental}

Os tratamentos constituíram um arranjo fatorial 4 x 10, envolvendo quatro espécies de pinus (P.taeda, P.oocarpa, P.elliottii e P.caribeae) e 10 tratamentos de inoculação, sendo nove isolados de rizobactéria e uma testemunha sem inoculação. O delineamento foi inteiramente casualizado, sendo mantidas cinco repetições por tratamento, cada uma constituída de 20 unidades amostrais.

\subsection{Obtenção e análise dos dados}

Aos 150 dias após a semeadura, avaliaram-se a altura da parte aérea e o diâmetro do coleto, bem como o peso de matéria seca das raízes e da parte aérea das mudas. A determinação do peso de matéria seca foi realizada após a separação da parte aérea do sistema radicular e secagem em estufa a $70^{\circ} \mathrm{C}$, até o material atingir peso constante. Os dados foram utilizados para cálculo do índice de qualidade de Dickson (IQD) (DICKSON, 1960), cuja fórmula é:

$\mathrm{IQD}=(\mathrm{PMSPA}+\mathrm{PMSR}) /((\mathrm{APA} / \mathrm{DC})+(\mathrm{PMSPA} / \mathrm{PMSR}))$ em que:

APA = altura da parte aérea da muda do colo até a ponta do broto mais alto $(\mathrm{cm})$;

DC $=$ diâmetro do coleto (na altura do colo da planta) (mm);

PMSPA = peso de matéria seca da parte aérea $(\mathrm{g})$; e

PMSR = peso de matéria seca de raízes $(\mathrm{g})$.

Os dados foram submetidos à análise de variância (ANOVA), aplicando-se o teste $\mathrm{F}$ a $5 \%$ de probabilidade, e as médias foram comparadas pelo teste de Tukey a 5\% de probabilidade, utilizando-se o programa SAEG (EUCLYDES, 1983).

\section{RESULTADOS E DISCUSSÕES}

\subsection{Especificidade dos isolados de rizobactérias}

Foram observados efeitos significativos dos isolados e das espécies de pinus, bem como a interação entre isolados de rizobactérias e espécies de pinus (Anexo 1). De modo geral, para todas as variáveis as mudas de $P$. taeda apresentaram melhores resultados que as demais espécies. Nas mudas de $P$. elliottii foram

R. Árvore, Viçosa-MG, v.31, n.6, p.1027-1033, 2007 
observados maiores pesos de matéria seca da parte aérea e do sistema radicular para um e três isolados, respectivamente. No entanto, para o índice de qualidade de Dickson não se observou diferença significativa dos isolados nessa espécie.

Independentemente dos tratamentos, foram observados maiores valores de PMSPA nas mudas de P. taeda. Quando se estudou o efeito do isolado dentro de cada espécie, somente foi observada diferença significativa em $P$. taeda, com as maiores médias obtidas das mudas desenvolvidas nos tratamentos com os isolados UFV-Z1e UFV-AM5 e as menores, dos isolados UFV-G4 e UFV-F6 (Quadro 1).
Com relação à variável PMSR, de modo geral também foram observados os melhores resultados nas mudas de $P$. taeda, seguidas de $P$. elliottii, destacando-se os isolados UFV-Z1 e UFV-AM5 em $P$. taeda e UFV-AM5, UFV-X2 e UFV-Z2 em $P$. elliottii (Quadro 2).

Com relação ao IQD, as maiores médias das mudas foram observadas, independentemente dos isolados, em $P$. taeda. Dentro dessa espécie, destacaram-se os isolados UFV-Z1 e UFV-AM5, sendo as piores médias nos isolados UFV-F6, UFV-G4 e UFV-G2. Nas demais espécies, não se observou efeito significativo dessa variável (Quadro 3).

Quadro 1 - Médias dos pesos de matéria seca da parte aérea de mudas de P. taeda, P. oocarpa, P. elliottii e P. caribeae var. hondurensis, aos 150 dias após a semeadura

Table 1 -Mean values of dry matter weight of the aerial part of P. taeda, P. oocarpa, P. elliottii and P. caribeae var. hondurensis seedlings at 150 days after sowing

\begin{tabular}{cccccc}
\hline Rizobactéria & $P$. taeda & $P$. oocarpa & $P$. elliottii & $P$. caribaea var. hondurensis & Média \\
\hline UFV-X2 & 1,4284 bc A & 0,4233 a B & 0,3975 a B & 0,3715 a B & $\mathbf{0 , 6 5 5 2}$ \\
UFV-Z1 & $\mathbf{1 , 8 1 7 7}$ a A & 0,3198 a B & 0,3352 a B & 0,2227 a B & $\mathbf{0 , 6 7 3 9}$ \\
UFV-AL9 & 1,4809 b A & 0,3577 a B & 0,3274 a B & 0,2672 a B & $\mathbf{0 , 6 0 8 3}$ \\
UFV-G2 & 1,2614 bcd A & 0,3678 a B & 0,396 a B & 0,2441 a B & $\mathbf{0 , 5 6 7 3}$ \\
UFV-G4 & 1,1025 d A & 0,3197 a B & 0,2399 a B & 0,2164 a B & $\mathbf{0 , 4 6 9 6}$ \\
UFV-AM2 & 1,4425 bcA & 0,3034 a B & 0,3011 a B & 0,3335 a B & $\mathbf{0 , 5 9 5 1}$ \\
UFV-F6 & 1,1018 dA & 0,3257 a B & 0,3435 a B & 0,2485 a B & $\mathbf{0 , 5 0 4 9}$ \\
UFV-F3 & 1,1664 cdA & 0,3113 a B & 0,3276 a B & 0,2104 a B & $\mathbf{0 , 5 0 3 9}$ \\
UFV-AM5 & $\mathbf{1 , 7 7 8 7}$ aA & 0,3905 a B & $\mathbf{0 , 4 8 1 8}$ a B & 0,2595 a B & $\mathbf{0 , 7 2 7 6}$ \\
TEST & 1,2519 bcdA & 0,3481 a B & 0,3551 a B & 0,3348 a B & $\mathbf{0 , 5 7 2 5}$ \\
\hline Média & $\mathbf{1 , 3 8 3 2 2}$ & $\mathbf{0 , 3 4 6 7 3}$ & $\mathbf{0 , 3 5 0 5 1}$ & $\mathbf{0 , 2 7 0 8 6}$ & \\
\hline
\end{tabular}

Médias seguidas de letras diferentes minúsculas nas colunas (rizobactérias) e maiúsculas nas linhas (espécies) diferem entre si, pelo teste de Tukey a $5 \%$ de probabilidade.

Quadro 2 - Média dos pesos de matéria seca do sistema radicular de mudas de $P$. taeda, P. oocarpa, P. elliottii e P. caribeae var. hondurensis, aos 150 dias após a semeadura

Table 2 - Mean values of dry matter of roots of P. taeda, P. oocarpa, P. elliottii and P. caribeae var. hondurensis seedlings at 150 days after sowing

\begin{tabular}{cccccc}
\hline Rizobactéria & $P$. taeda & $P$. oocarpa & $P$. elliottii & $P$. caribaea var. hondurensis & Média \\
\hline UFV-X2 & 0,4974 ab A & 0,3042 a B & $\mathbf{0 , 5 4 8 3}$ ab A & 0,1648 a B & $\mathbf{0 , 3 7 8 7}$ \\
UFV-Z1 & $\mathbf{0 , 6 7 1 7}$ a A & 0,2578 a C & 0,4624 bc B & 0,1572 a C & $\mathbf{0 , 3 8 7 3}$ \\
UFV-AL9 & 0,5941 ab A & 0,2819 a BC & 0,4516 bc AB & 0,2089 a C & $\mathbf{0 , 3 8 4 1}$ \\
UFV-G2 & 0,4312 bc AB & 0,2649 a BC & $\mathbf{0 , 5 4 6 3}$ ab A & 0,1648 a C & $\mathbf{0 , 3 5 1 8}$ \\
UFV-G4 & 0,3971 c A & 0,2497 a AB & 0,3309 c AB & 0,2005 a B & $\mathbf{0 , 2 9 4 6}$ \\
UFV-AM2 & 0,5027 ab A & 0,2629 a BC & 0,4154 bc AB & 0,2002 a C & $\mathbf{0 , 3 4 5 3}$ \\
UFV-F6 & 0,3846 c AB & 0,1984 a BC & 0,4739 abc A & 0,1572 a C & $\mathbf{0 , 3 0 3 5}$ \\
UFV-F3 & 0,4644 bc A & 0,2401 a B & 0,4518 bc AB & 0,1696 a B & $\mathbf{0 , 3 3 1 5}$ \\
UFV-AM5 & $\mathbf{0 , 6 6 4 3}$ a A & 0,278 a B & $\mathbf{0 , 6 6 4 6}$ a A & 0,1757 a B & $\mathbf{0 , 4 4 5 7}$ \\
TEST & 0,4813 bc A & 0,2262 a B & 0,4898 abc A & 0,2052 a B & $\mathbf{0 , 3 5 1 1}$ \\
\hline Média & $\mathbf{0 , 5 0 8 8}$ & $\mathbf{0 , 2 5 6 4}$ & $\mathbf{0 , 4 8 3 5}$ & $\mathbf{0 , 1 8 0 4}$ &
\end{tabular}

Médias seguidas de letras diferentes minúsculas nas colunas (rizobactérias) e maiúsculas nas linhas (espécies) diferem entre si, pelo teste de Tukey a $5 \%$ de probabilidade.

R. Árvore, Viçosa-MG, v.31, n.6, p.1027-1033, 2007 
Quadro 3 - Índice de qualidade de Dickson de mudas de P. taeda, P. oocarpa, P. elliottii e P. caribeae var. hondurensis, aos 150 dias após a semeadura

Table 3 - Dickson's quality index of P. taeda, P. oocarpa, P. elliottii and P. caribeae var. hondurensis seedlings after 150 days after sowin

\begin{tabular}{cccccc}
\hline Rizobactéria & $P$. taeda & $P$. oocarpa & $P$. elliottii & $P$. caribaea var. hondurensis & Média \\
\hline UFV-X2 & 0,6427 bcd A & 0,1061 a B & 0,145 a B & 0,0883 a B & $\mathbf{0 , 2 4 5 5 2 5}$ \\
UFV-Z1 & $\mathbf{0 , 8 8 4 5}$ a A & 0,0921 a B & 0,1263 a B & 0,0504 a B & $\mathbf{0 , 2 8 8 3 2 5}$ \\
UFV-AL9 & 0,7917 abc A & 0,0943 a B & 0,1257 a B & 0,0667 a B & $\mathbf{0 , 2 6 9 6}$ \\
UFV-G2 & 0,5514 d A & 0,099 a B & 0,1389 a B & 0,0536 a B & $\mathbf{0 , 2 1 0 7 2 5}$ \\
UFV-G4 & 0,5132 d A & 0,0888 a B & 0,0884 a B & 0,0595 a B & $\mathbf{0 , 1 8 7 4 7 5}$ \\
UFV-AM2 & 0,6496 bcd A & 0,0875 a B & 0,1088 a B & 0,0723 a B & $\mathbf{0 , 2 2 9 5 5}$ \\
UFV-F6 & 0,4937 d A & 0,0725 a B & 0,2987 a AB & 0,0527 a B & $\mathbf{0 , 2 2 9 4}$ \\
UFV-F3 & 0,6162 cd A & 0,0871 a B & 0,1139 a B & 0,0519 a B & $\mathbf{0 , 2 1 7 2 7 5}$ \\
UFV-AM5 & $\mathbf{0 , 8 7 0 8}$ ab A & 0,1054 a B & 0,1802 a B & 0,0601 a B & $\mathbf{0 , 3 0 4 1 2 5}$ \\
TEST & 0,6356 cd A & 0,0891 a B & 0,1345 a B & 0,0706 a B & $\mathbf{0 , 2 3 2 4 5}$ \\
\hline Média & $\mathbf{0 , 6 6 4 9}$ & $\mathbf{0 , 0 9 2 1}$ & $\mathbf{0 , 1 4 6 0}$ & $\mathbf{0 , 0 6 2 6}$ & \\
\hline
\end{tabular}

Médias seguidas de letras diferentes minúsculas nas colunas (rizobactérias) e maiúsculas nas linhas (espécies) diferem entre si, pelo teste de Tukey a $5 \%$ de probabilidade.

Neste estudo foi constatada interação significativa entre isolados de rizobactérias e espécies de Pinus sp. De modo geral, dos nove isolados testados, apenas UFV-Z1 e UFV-AM5 destacaram-se dos demais, resultando em estímulo ao crescimento e aumento na qualidade de mudas de P.taeda.

Os dados indicam que, em todos os isolados, apenas as mudas de P. taeda apresentaram ganhos de peso de matéria seca radicular e da parte aérea e de índice de qualidade. Dessa forma, as rizobactérias obtidas de $P$. taeda não promoveram efeito significativo sobre o crescimento das mudas das outras espécies testadas, quando aplicadas no substrato para produção de mudas.

Embora seja bastante estudado, ainda não existe um consenso sobre a existência de especificidade das rizobactérias. Enebak (2005), ao inocular isolados obtidos de $P$. taeda em $P$. taeda, P. elliottii e $P$. palustris, constatou que a altura da parte aérea das mudas foi incrementada por cinco de oito isolados testados em mudas de $P$. taeda e em três nas de $P$. elliottii. No entanto, apenas um isolado incrementou a biomassa radicular em $P$. taeda. O referido autor verificou, ainda, que a especificidade das bactérias inoculadas em mudas de pinus existe e pode ser evidenciada em viveiros de produção de mudas. Porém, a especificidade não deve ser analisada isoladamente, pois outros fatores podem estar relacionados com essa incompatibilidade, como: dose da bactéria inoculada e interferência de alguns patógenos preexistentes no substrato que podem afetar o crescimento (VONDERWELL e ENEBAK, 2000).
Alguns estudos têm demonstrado existência de especificidade de resposta de espécies arbóreas a rizobactérias, portanto isolados promotores de crescimento em uma espécie de planta podem não ser efetivos para outras (SCHROTH e HANCOCK, 1982; CHANWAY e HOLL, 1993). Diferenças na quantidade e qualidade de exsudados radiculares de diversas espécies de plantas, bem como de cultivares e genótipos de uma mesma espécie, têm sido relatadas como a causa dessas variações (BALDANI e DOBEREINER, 1980).

Outra importante variável na avaliação da qualidade das mudas utilizadas neste estudo foi o índice de qualidade de Dickson. Mudas de P. taeda e P. elliottii apresentaram valores superiores ao recomendado, enquanto as de $P$. oocarpa e $P$. caribaea var. hondurensis foram inferiores, independentemente do tratamento com rizobactérias. Pode-se observar, também, que as mudas que exibiram maiores índices de qualidade também obtiveram ganho de peso de matéria seca da parte aérea e do sistema radicular em relação à testemunha, mostrando que houve correlação entre as variáveis e o índice empregado.

Segundo Johnson e Cline (1991), o índice de qualidade de Dickson (IQD) é uma medida morfológica integrada, e o valor mínimo considerado padrão para mudas produzidas em tubetes de 50 ou $60 \mathrm{~mL}$, recomendado por Hunt (1990), é de 0,20. Os baixos valores obtidos neste estudo podem estar ligados às condições ambientais de experimentação não-otimizadas para produção de mudas de cada espécie, pois as espécies de pinus testadas, por pertencerem a diversas 
regiões, têm diferentes exigências quanto a temperatura, déficit hídrico, umidade e radiação solar.

O índice de qualidade de Dickson é um bom indicador da qualidade das mudas, pois são considerados, para o seu cálculo, o vigor e o equilíbrio da distribuição da biomassa na muda, ou seja, ele pondera os resultados de muitas variáveis. As variáveis morfológicas e os índices utilizados para avaliação da qualidade das mudas podem ser utilizados isoladamente ou em conjunto, para classificação do padrão da qualidade de mudas, desde que sejam empregados em mudas desenvolvidas em condições de ambiente semelhantes (FONSECA, 2002).

Como os estudos de especificidade de rizobactérias obtidos de mudas de $P$. taeda são escassos, é necessário realizar pesquisas para que se obtenham isolados que não sejam específicos para diferentes espécies de Pinus sp., o que viabilizaria a produção e utilização dessas rizobactérias em nível comercial.

\section{CONCLUSÕES}

- Dentre nove isolados testados quanto à especificidade em quatro espécies de Pinus, apenas o isolado UFV-AM5 não se mostrou específico para as variáveis biomassa de parte aérea e sistema radicular, em duas das quatro espécies estudadas ( $P$. taeda e P. elliottii).

- Os incrementos em biomassa de parte aérea e do sistema radicular e no índice de qualidade de Dickson variaram conforme o isolado e a espécie de pinus, porém, de modo geral, observaram-se maiores médias em $P$. taeda.

- Em P. taeda, a eficiência dos isolados UFV-Z1 e UFV-AM5 foi praticamente a mesma nos três parâmetros testados e superior à dos demais isolados.

- Em P. elliottii, o isolado UFV-AM5 foi o que proporcionou maior aumento de biomassa da parte aérea e do sistema radicular".

\section{REFERÊNCIAS}

BALDANI, V. L. D.; DOBEREINER, J. Host plant specificity in the infection of cereals with Azospirillum spp. Soil Biology Biochemistry, v. 12, p.433-439, 1980.

R. Árvore, Viçosa-MG, v.31, n.6, p.1027-1033, 2007
BENT, E. The effect of other rhizosphere microorganisms on the ability of Paenibacillus spp. to promote the growth of lodgepole pine [Pinus contorta var. latifolia (Dougl. Engelm.)]. 2000. $128 \mathrm{f}$. Thesis (Ph.D.) - University of British Columbia, Vancouver, 2000.

CHANWAY, C. P. Differential response of western hemlock from low and high elevations to inoculation with plant growthpromoting Bacillus polymyxa. Soil Biology Biochemystry, v.27, p.767-775, 1995.

CHANWAY, C. P. Inoculation of tree roots with plant growth promoting soil bacteria: An emerging technology for reforestation. Forest Science, v.43, p.99-112, 1997.

CHANWAY, C. P.; HOLL, F. B. Ecotypic specificity of spruce emergence-stimulating Pseudomonas putida. Forest Science, v.39, p.520-527, 1993.

CHANWAY, C. P.; HOLL, F. B. Influence of soil biota on Douglas-fir (Pseudotsuga menziesii) seedling growth: The role of rhizosphere bacteria. Canadian Journal of Botany, v.70, p.1025-1031, 1992.

CHANWAY, C. P.; HOLL, F. B.; TURKINGTON, R. Genotypic coadaptation in growth promotion of forage species by Bacillus polymixa. Plant and Soil, v.106, p.281-284, 1988.

DICKSON, A.; LEAF, A. L.; HOSNER, J. F. Quality appraisal of white spruce and white pine seedling stock in nurseries. Forest Chronicle, v.36, p.10-13, 1960.

ENEBAK, S. A. Rhizobacteria Isolated from loblolly pine seedlings mediate growthpromotion of greenhouse-grown loblolly, slash, and longleaf pine seedlings. Forest Science, v.51, n.6, p.541-545, 2005.

ENEBAK, S. A.; WEI, G.; KLOEPPER, J. W. Effects of plant growth-promoting rhizobacteria on loblolly and slash pine seedlings. Forest Science, v.44, n.1, p.139-144, 1998. 
ENEBAK, S. A.; CAREY, W. A. Plant growthpromoting rhizobacteria induced systemic resistance to fusiform rust in naturally inoculated loblolly seedlings. Southern Journal of Applied Forestry, v.28, p.185-188, 2004.

EUCLYDES, R. F. Manual de utilização do programa SAEG (Sistema para Análises Estatística e Genética). Viçosa, MG: Universidade Federal de Viçosa, 1983. 59p.

FONSECA, E. P. et al. Padrão de qualidade de mudas de Trema micrantha (L.) Blume, produzidas sob diferentes períodos de sombreamento.

Revista Árvore, v.26, n.4, p.515-523, 2002.

\section{FOOD AND AGRICULTURE ORGANIZATION OF THE UNITED}

NATIONS - FAO. Disponível em:

(www.fao.org) Acesso em: 18 jul. de 2006.

HOLL, F. B.; CHANWAY, C. P. Rhizosphere colonisation e seedling growth promotion of lodgepole pine by Bacillus polymyxa.

Canadian Journal of Microbiology, v.38, p.303-308, 1992.

HUNT, G. A. Effect of styroblock design e cooper treatment on morphology of conifer seedlings. In: TARGET SEEDLING SYMPOSIUM, MEETING OF THE WESTERN FOREST NURSERY ASSOCIATIONS, GENERAL TECHNICAL REPORT RM-200. 1990, Roseburg. Proceedings... Fort Collins: United States Departament of Agriculture, Forest Service, 1990. p.218-222.

JOHNSON, J. D.; CLINE, P. M. Seedling quality of southern pines. In: DUREYA, M. L.; DOUGHERTY, P. M. (Eds.). Forest regeneration manual. Dordrecht: Kluwer Academic Publishers, 1991.p.143-162.

KADO, C. J.; HESKETT, M. G. Selective media for isolation of Agrobacterium, Corynebacterium, Erwinia, Pseudomonas and Xanthomonas.

Phytopathology, v.60, p.969-976, 1970.

LEYVAL, C.; BERTHELIN, J. Rhizodeposition and net release of soluble organic compounds by pine and beech seedlings inoculated with rhizobacteria and ectomycorrhizal fungi. Biology e Fertility of Soils, v.15, p.259-267, 1993.
MAFIA, R. G. et al. Crescimento de mudas e produtividade de minijardins clonais de eucalipto tratados com rizobactérias selecionadas. Revista Árvore, v.29, n.6, p.843-851, 2005.

NEVES, G. A. et al. Análise econômico-financeira da exploração de pinus resinífero em pequenos módulos rurais. Sorocaba: Programa de Estudos dos Negócios do Sistema Agroindustrial/ Universidade de São Paulo, 2001. 57p. (Monografia apresentada ao PENSA).

PARKER, A. K.; DANGERFIELD, J. A. Influence of bacterial inoculations on growth of containerized Douglas fir seedlings. Canadian For Serv. Bimonth. Res. Notes, v. 31, p.14-15, 1975.

POKOJSKA-BURDZIEJ, A. The effect of microorganisms, microbial metabolites and plant growth regulators (IAA and GA 3 ) on the growth of pine seedlings (Pinus sylvestris L.). Polish Journal of Soil Science, v.15, p.137-143, 1982.

PROBANZA, A. et al. Pinus pinea $\mathrm{L}$. seedling growth and bacterial rhizosphere structure after inoculation with PGPR Bacillus (B. licheniformis CECT 5106 and B. pumilus CECT 5105). Applied Soil Ecology, v.20, p.75-84, 2002.

SCHROTH, M. N.; HANCOCK, J. G. Diseasesuppressive soil and root-colonizing bacteria. Science, v.216, p.1376-1381, 1982.

TEIXEIRA, D. A. Promoção de enraizamento e indução de resistência sistêmica à ferrugem e à mancha-de-Cylindrocladium, mediadas por rizobactérias em clones de Eucalyptus spp. 2001. 67f. Tese (Doutorado em Fitopatologia) - Universidade Federal de Viçosa, Viçosa, MG, 2001.

VONDERWELL, J.; ENEBAK, S. A. Differential effects of rhizobacteria strain and dose on the ectomycorrhizal colonization of loblolly pine seedlings. Forest Science, v.46, p.437-441, 2000.

R. Árvore, Viçosa-MG, v.31, n.6, p.1027-1033, 2007 


\section{ANEXO}

Quadro ANOVA mostrando a interação isolado de rizobactéria e espécie de pinus ANOVA table presenting the interaction among rhizobacterias and pine species.

\begin{tabular}{|c|c|c|c|}
\hline & Fonte de variação & Quadrado médio & F Sig. \\
\hline \multicolumn{4}{|l|}{ BIOMASSA PARTE AÉREA } \\
\hline Isolado & $0,8751858 \mathrm{E}-01$ & 4,94 & $* *$ \\
\hline Espécie de Pinus & 13,01726 & 735,44 & $* *$ \\
\hline Isolado*Espécie de Pinus & $0,5050082 \mathrm{E}-01$ & 2,85 & $* *$ \\
\hline Resíduo & $0,1769998 \mathrm{E}-01$ & & \\
\hline \multicolumn{4}{|l|}{ BIOMASSA RAIZ } \\
\hline Isolado & $0,3045275 \mathrm{E}-01$ & 4,36 & $* *$ \\
\hline Espécie de Pinus & 1,252636 & 179,21 & $* *$ \\
\hline Isolado*Espécie de Pinus & $0,1665042 \mathrm{E}-01$ & 2,38 & $* *$ \\
\hline Resíduo & $0,6989834 \mathrm{E}-02$ & & \\
\hline \multicolumn{4}{|c|}{ INDICE QUALIDADE DICKSON } \\
\hline Isolado & $0,2145304 \mathrm{E}-01$ & 2,00 & $* *$ \\
\hline Espécie de Pinus & 3,994726 & 373,24 & $* *$ \\
\hline Isolado*Espécie de Pinus & $0,2653516 \mathrm{E}-01$ & 2,48 & $* *$ \\
\hline Resíduo & $0,1070284 \mathrm{E}-01$ & & \\
\hline
\end{tabular}

** Significativo pelo teste de Tukey (5\%). 